\title{
PENGELOLAAN BANK PLASTIK DALAM UPAYA PENINGKATAN EKONOMI DAN KEBERSIHAN DI DESA WISATA CEPAKA
}

\author{
Ni Nyoman Sri Rahayu Trisna Dewi ${ }^{1 *)}$, Tiara Kusuma Dewi \\ (Universitas Triatma Mulya ${ }^{\mathbf{1 , 2}}$ ) \\ rahayu.trisna@triatmamulya.ac.id ${ }^{*}$
}

\begin{abstract}
Garbage is a major problem in the community which can cause environmental pollution, the daily life of the village community is more about processing the final waste by burning it at a certain time, therefore with the existence of a waste bank there will be an increase in environmental awareness and perhaps economic awareness. The Garbage Bank is a business entity engaged in inorganic waste management. People can sort and save waste at the Garbage Bank, so that it can generate economic value. The Garbage Bank serves customers in saving waste, but most of the Garbage Bank still uses conventional transaction facilities, which causes the transaction data to be lost, damaged, or inaccurate calculation of transaction data. The Garbage Bank also serves garbage collection to customer locations around the Garbage Bank. This research has the main objective to provide assistance in the making and provision of administrative bookkeeping to the Management of the Cepaka Harum Plastic Bank.
\end{abstract}

Keywords: garbage bank.

\section{PENDAHULUAN}

Sampah merupakan material sisa yang tidak diinginkan setelah berakhirnya suatu proses. Permasalahan sampah selalu menjadi perhatian pemerintah dan seolah-olah tidak ada ujungnya. Sampah selalu dihasilkan oleh setiap rumah tangga sementara tempat pembuangan sampah mulai penuh dan menimbulkan berbagai permasalahan serius, seperti polusi bagi masyarakat sekitarnya. Sampah dapat menjadi penyebab rusaknya lingkungan melalui pembuangan limbah sampah, jenis-jenis sampah yang berbahaya seperti sampah medis, serta sampah yang sulit diuraikan seperti sampah plastik. Untuk mengurai sampah plastik diperlukan waktu puluhan bahkan ratusan tahun, bahkan parahnya saat terurai partikel-partikel plastik akan mencemari tanah dan air tanah. Jika sampah plastik dibakar,akan menghasilkan asap beracun yang berbahaya bagi kesehatan. Selainitu, sampah-sampah tersebut akan menambah kadar gas rumah kaca di atmosfer. Menurut Widawati dan Ikmah (2019) sampah yang tidak dikelola dengan baik akan menimbulkan beberapa dampak, yaitu sampah dapat menjadi sumber penyakit dan lingkungan menjadi kotor, pembakaran sampah dapat mengakibatkan pencemaran udara dan memicu terjadinya pemanasan global, pembusukan sampah dapat menimbulkan bau yang tidak sedap dan berbahaya bagi kesehatan, serta pembuangan sampah ke sungai dapat 
menimbulkan pendangkalan sungai sehingga akan memicu terjadinya banjir.

Di Bali terdapat tempat pembuangan sampah yang sudah mulai dipenuhi oleh timbunan sampah. Sehingga pemerintah perlu menciptakan solusi agar sampah yang jumlahnya semakin banyak tersebut bisa diatasi. Di tengah permasalahan tersebut, desa-desa di Bali mulai membuat berbagai inovasi untuk membantu pemerintah mengatasi permasalahan sampah yang seolah tidak pernah berhenti. Beberapa inovasi yang mulai dimunculkan antara lain menciptakan gudang pengolahan sampah agar dapat memberikan manfaat, menciptakan bank sampah, dan lain sebagainya. Widawati dan Ikmah (2019) menyatakan, sampah yang dikelola dengan baik selain akan mendatangkan keuntungan ekonomi juga keuntungan sosial seperti kesehatan dan estetika lingkungan.

Desa Cepaka menjadi salah satu desa yang berusaha membantu menyediakan solusi terhadap permasalahan sampah yang terjadi. Meskipun dalam kondisi masih rendahnya kesadaran masyarakat terhadap kebersihan lingkungan dan minimnya fasilitas kebersihan. Berdasarkan data yang diperoleh, desa Cepaka menghasilkan sampah plastik sebanyak $1.122 \mathrm{~kg}$ dengan jumlah masyarakat sebanyak $139 \mathrm{kk}$ dalam kurun waktu 6 bulan dari bulan Agustus 2020 sampai bulan Januari 2021.Jumlah tersebut merupakan jumlah yang lumayan besar sebagai penghasil sampah plastic yang akan menyumbang timbunan sampah di tempat pembuangan sampah. Di tengah keterbatasan yang dimiliki, Desa Cepaka berusaha untuk menciptakan inovasi bank plastik di Desa Cepaka untuk membantu dalam pengelolaan permasalahan sampah yang terjadi. Bank plastik yang didirikan tersebut diberikan nama "Bank Plastik Cepaka Harum".Melalui bank plastik tersebut, masyarakat diajarkan konsep untuk menjual sampah plastik mereka ke bank plastik Desa Cepaka dengan harapan dapat mengurangi kuantitas sampah yang akan dikirim ke tempat pembuangan akhir. Menurut Sekarningrum, dkk (2017) tujuan bank sampaha dalah mengurangi sampah dari sumbernya dengan cara mendiidk masyarakat, menciptakan lingkungan dan wilayah yang layak huni, mengurangi penyakit kejiwaan di masyarakat, meningkatkan nilai tambah ekonomi anggitanya melalui bisnis turunannya, menciptakan kerukunan sesama warga, dan menciptakan kepercayaan diri terhadap lingkungannya.

Bank Plastik Cepaka Harum terletak di desa Cepaka Tabanan Bali. Bank plastik ini merupakan unit usaha bersama milik desa. Jumlah pengurus Bank Plastik ini berjumlah 2 orang. Bank Plastik Cepaka Harum ini mengelola sampah anorganik berupa sampah plastik, besi dan kaca. Sampah anorganik berasal dari nasabah individu, kelompok unit Bank Cepaka, dan perumahan.

Bank Plastik Cepaka Harum merupakan sistem kolaborasi perbankan pada umumnya dimana nasabah menyetorkan tabungannya dalam bentuk sampah anorganik yang sudah dipilah sebelumnya secara mandiri kemudian dicatat dalam buku tabungan dalam bentuk nominal uang atau rupiah yang bisa dicairkan kapan saja.Proses pencatatan tersebut dilakukan secara konvensional oleh 
tenaga administrasi yang sekaligus merangkap sebagai tenaga lapangan. Dalam pengoperasian Bank Plastik Cepaka Harum, terdapat beberapa permasalahan yang terjadi, antara lain:

a. Proses pencatatan transaksi secara konvensional dapat menimbulkan risiko, seperti data transaksi mudah/ bisa hilang dan rusak

b. Rendahnya pemahaman mengenai pembukuan sehingga susah menghitung untung dan rugi yang diperoleh

c. Rendahnya pengendalian internal karena tugas rangkap yang dilakukan oleh satu petugas

d. Terjadi fluktuasi harga beli dari pengepul karena tidak ada kerjasama dengan satu pengepul utama

e. Pencemaran lingkungan yang bersumber dari sampah yang diakibatkan oleh rendahnya kesadaran masyarakat terhadap pentingnya pengelolaan sampah

Desa Cepaka sebagai desa mitra Universitas Triatma Mulya telah memiliki bank sampah, namun keterbatasan ilmu pengetahuan mereka tentang pembukuan menjadi kendala dalam mengetahui untung dan ruginya bank sampah. Kompetensi yang dibutuhkan oleh Desa Cepaka dimiliki oleh dosen dan mahasiswa secara utuh, sehingga implementasi program PKM ini berpotensi dapat dilaksanakan secara optimal.

Berdasarkan permasalahan yang terjadi, maka tujuan program PKM adalah sebagai berikut:

1. Meningkatkan pengetahuan pengurus Bank Plastik Cepaka Harum mengenai pembukuan pengelolaan keuangan yang baik dan sederhana.
2. Memberikan referensi pengepul agar dapat bekerjasama antara pengurus dan pengepul untuk menciptakan kestabilan harga sampah anorganik dari resiko naik turunnya harga secara signifikan. Terkadang dalam keadaan sampah plastik yang sudah terkumpul dan siap dikirim ke pengepul mengalami penurunan harga yang cukup besar yang bisa mengakibatkan menurunnya pendapatan yang diterima oleh pengurus Bank Plastik Cepaka Harum.Jika dibiarkan secara berkelanjutan maka proses untuk memperoleh keuntungan maupun kemajuan dari usaha Bank plastik itu sendiri akan terhambat.

3. Memberikan pemahaman pentingnya pemisahan tugas dan membuat Standar Operasonal Kerja (SOP) untuk Pengurus Bank Plastik Cepaka Harum dalam membagi tugas dan tanggung jawabnya masing-masing antara bagian administrasi dan bagian lapangan supaya bekerja secara optimal.

4. Memberikan arahan tentang menjaga kebersihan tempat kerja dari tumpukan-tumpukan sampah organik yang sudah tidak terpakai dan melakukan kegiatan gotong royong bersama Kepala Desa Cepaka beserta masyarakat Desa Cepaka untuk membersihkan area Bank Plastik Cepaka Harum dari tumpukan sampah-sampah lama yang tidak bisa di daur ulang/ sampah organik supaya menciptakan suasana nyaman dan mengurangi bau-bau kurang sedap yang ditimbulkan oleh sampah organik tersebut. 


\section{METODE PELAKSANAAN}

Metode pelaksanaan kegiatan PKMpada Bank Plastik Cepaka Harum dilakukan melalui penyuluhan, pelatihan, dan pendampingan. Tahap pertama yang dilakukan yaitu membantu mitra menjalin kerja sama dengan pengepul, dimana mitra telah diberikan beberapa referensi pengepul dari seluruh area Tabanan yang bertujuan untuk menjaga kestabilan harga pasar untuk sampah plastik yang akan dijual dan meminimalisir tingkat resiko turunnya harga secara drastis. Berikutnya diberikan pelatihan dan pendampingan kepada pengurus Bank Plastik Cepaka Harum tentang proses pembukuan pengelolaan keuangan yang baik dan sederhana. Dengan demikian diharapkan proses transaksi di Bank Plastik Cepaka Harum bisa berjalan lancar dan bisa lebih terkontrol, dan juga dapat mengetahui pemasukan dan pengeluaran setiap harinya beserta dapat membuat laporan harian dan bulanan supaya bisa memperkirakan keuntungan maupun kerugiannya. Berikutnya diberikan pemahaman kepada pengurus Bank Plastik Cepaka Harum mengenai pentingnya pengendalian internal dengan tidak membebankan tugas rangkap hanya kepada satu orang saja sehingga kemungkinann terjadinya kesalahan terutama dalam pencatatan keuangan dapat diminimalisir. Terakhir, dilaksanakan pendampingan untuk melaksanakan kegiatan kerja bakti bersama di seluruh area Bank Plastik Cepaka Harum supaya menciptakan suasana nyaman dan mengurangi bau-bau yang kurang sedap akibat dari sampah organik.
Penerapan

teknologi

dilakukan melalui beberapa metode pembelajaran, yaitu :

1. Memberikan pelatihan dan pendampingan dalam membuat pembukuan yang sederhana sehingga diketahui pemasukan dan pengeluaran

2. Memberikan referensi pengepul

3. Penyuluhan dan pelatihan serta monitoring mengenai proses dari awal pengambilan sampah anorganik dari rumah-rumah warga sebagi nasabah sampai dikumpulkan di Bank Plastik Cepaka harum hingga proses pemisahan sesuai dengan jenisjenisnya

4. Kerja bakti membersihkan seluruh area Bank Cepaka Harum dari sampah-sampah lama organik.

\section{HASIL DAN PEMBAHASAN}

Berdasarkan tujuan dari pelaksanaan kegiatan PKM, terdapat beberapa program yang dapat direalisasikan pada Bank Plastik Cepaka Harum, yaitu:

1. Pelatihan dan pendampingan pembuatan laporan keuangan dan perekapan buku tabungan. Kegiatan ini dilaksanakan dengan memberikan pemahaman dasar mengenai pembukuan dan proses pembuatan laporan keuangan sehingga ke depannya mitra dapat menghitung untung dan rugi yang diperoleh dari Bank Plastik Cepaka Harum.

2. Memberikan beberapa referensi pengepul sampahanorganik. Kegiatan ini dilaksanakan dengan cara mencarikan beberapa pengepul di seluruh area Tabanan dengan mencari pengepul yang bersedia membeli sampah plastik dengan harga yang lebih tinngi 
dan menjalin hubungan untuk melakukan kerja sama dangan Bank Plastik Cepaka Harum. Program ini dapat membantu menyelesaikan permasalahan mitra yang terjadi selama ini, dimana pengepul yang membeli sampah plastiknya berbeda-beda sehingga menyebabkan fluktuasi harga bahkan penawaran harga yang tidak wajar.

3. Mengikuti proses pengambilan sampah anorganik dari rumahrumah warga yang menjadi nasabah mitra. Program ini dilaksanakan dengan mengikuti pengurus Bank Plastik Cepaka Harum dalam pengambilan sampah-sampah ke beberapa rumah warga mulai dari melakukan penimbangan sampah serta pencatatan berat sampah.

4. Melaksanakan gotong royong bersama untuk membersihkan seluruh area Bank Plastik Cepaka Harum. Kegiatan ini juga didukung oleh bapak Kepala Desa Cepaka, DKP Desa Cepaka dan elemen masyarakat yang terlibat. Kegiatan in meliputi pembersihan di Area Bank Plastik Cepaka Harum serta memberikan bantuan berupa drum pembakaran sampah organik yang bebas polusi, karena drum dilengkapi dengan penutup yang dapat mengurangi penyebaran polusi asap pembakaran sampah. Secara ringkas, hasil pelaksanaan kegiatan PKM ini dapat dilihat pada Tabel 1.

Tabel 1

Pelaksanaan kegiatan KKN di Bank Plastik Cepaka Harum

\begin{tabular}{|c|c|c|c|c|}
\hline \multirow[b]{2}{*}{ No } & \multicolumn{4}{|c|}{ Sasaran Program } \\
\hline & Kegiatan & & Tempat & Biaya \\
\hline \multirow[t]{6}{*}{1} & referensi 10 Des & Pengepul & Seluruh & \\
\hline & pengepul di seluruh area 2020 & sampah anorganik & Area & \\
\hline & Tabanan dan menjalin $(09.00$ & & Tabanan & - \\
\hline & hubungan untuk melakukan Wita & & & \\
\hline & kerja sama dangan Bank selesai) & & & \\
\hline & Plastik Cepaka Harum & & & \\
\hline
\end{tabular}

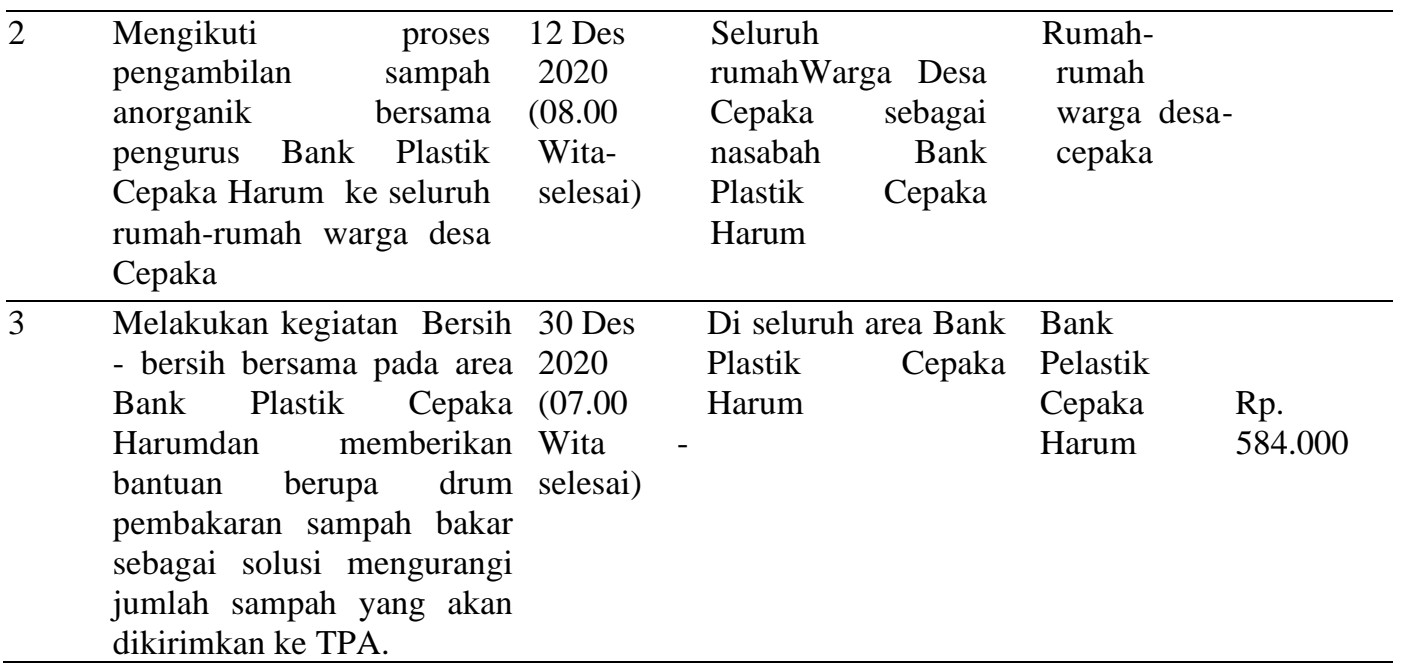


SAVE: Synergy and Society Service

Vol 1, No 1, Juni 2021 hal. 1 - 7

(Ni Nyoman Sri Rahayu Trisna Dewi ${ }^{1}$, Tiara Kusuma Dewi ${ }^{2}$ )

\begin{tabular}{|c|c|c|c|c|c|c|}
\hline 4 & $\begin{array}{l}\text { Memberikan pelatihan, } \\
\text { pendampingan } \\
\text { pembekalan tentang proses } \\
\text { pembukuan, pengelolaan } \\
\text { keuangan dan membantu } \\
\text { merapikan laporan } \\
\text { keuangan dan perekapan } \\
\text { buku tabungan }\end{array}$ & $\begin{array}{l}\text { 2Jan } \\
2021 \\
(09.00 \\
\text { Wita- } \\
\text { selesai) }\end{array}$ & $\begin{array}{l}\text { Pengurus } \\
\text { Plastik } \\
\text { Harum }\end{array}$ & $\begin{array}{r}\text { Bank } \\
\text { Cepaka }\end{array}$ & $\begin{array}{l}\text { Bank } \\
\text { Plastik } \\
\text { Cepaka } \\
\text { Harum }\end{array}$ & - \\
\hline
\end{tabular}

Pada Bank Plastik Cepaka Harum limbah yang diolah hanya limbah anorganik, sampah yang sudah dikumpulkan dari para nasabah selanjutnya akan dikelompokkan berdasarkan jenisnya kemudian dilakukan pengumpulan sesuai tempat yang ditentukan, seperti botol mineral dipisahkan dari botol beserta label. Sampah yang terdapat di Bank Plastik Cepaka Harum didominasi oleh sampah plastik. Pengelolaan dari limbah ini diharapkan berdampak positif mulai hal kecil seperti orang mampu membuang sampah pada tempatnya, kemudian kegiatan ini mampu mengurangi jumlah sampah yang ada di TPA, kemudian mampu menjadi sumber perekonomian masyarakat sebagai tambahan untuk membeli sembako, token listrik, air dan PLN. Yang terakhir adalah meningkatkan keterampilan masyarakat dengan mengelola limbah anorganik menjadi barang yang lebih bermanfaat.

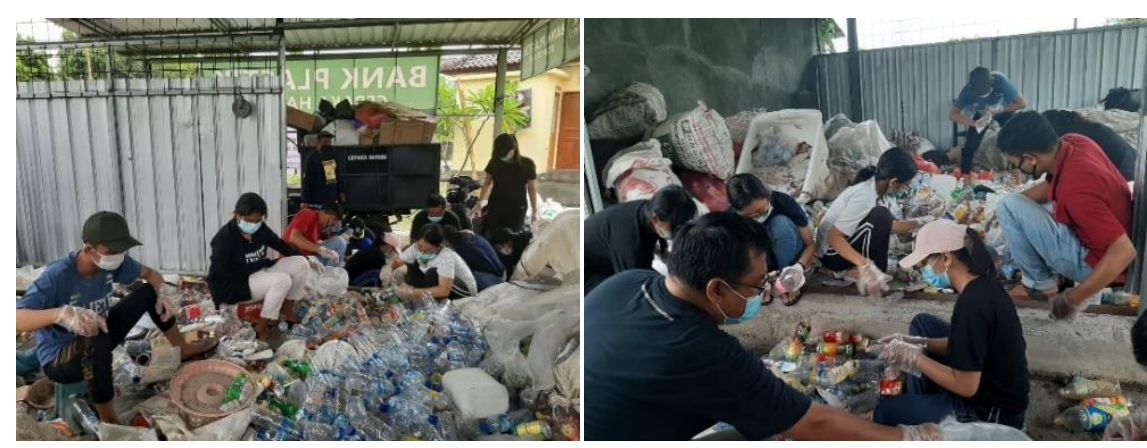

Gambar 1

Proses pemilahan jenis-jenis sampah

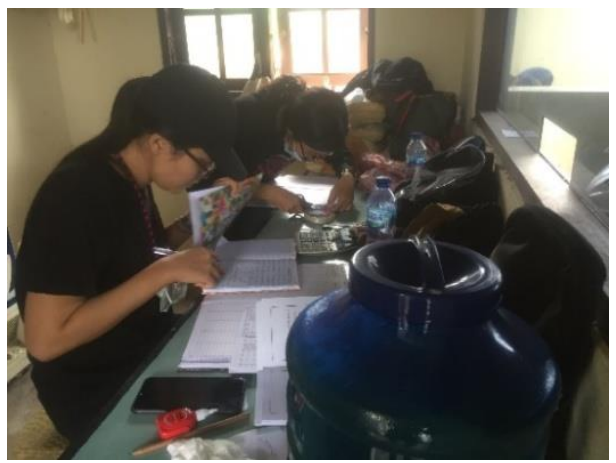

Gambar 2

Pelatihan dan Pendampingan Pembukuan 


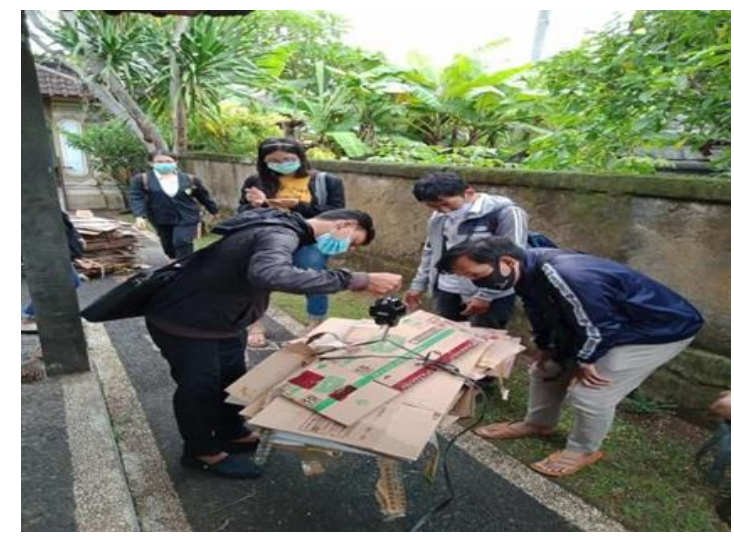

Gambar 3

Proses Pengambilan Sampah ke Nasabah

\section{KESIMPULAN}

Berdasarkan hasil pelaksanaan PKM di Bank Plastik Cepaka Harum dapat disimpulkan sebagai berikut :

1. Telah terbentuk pemahaman dari para pengurus Bank Plastik Cepaka Harum tentang proses pembukuan secara benar seperti laporan harian, bulanan dan laporan laba rugi.

2. Telah diberikan referensi kerja sama antara pengurus Bank Plastik Cepaka Harum dengan pengepul.

3. Telah diberikan pemahaman kepada Pengurus Bank Plastik Cepaka Harum pentingnya pembagian tugas dan tanggung jawab antara bagian administrasi dan bagian lapangan.

4. Membuat seluruh area di sekitar Bank Plastik Cepaka Harum lebih bersih, rapi, dan mengurangi bau akibat sampah organik melalui kerja bakti gotong royong.

5. Memberikan sebuah drum pembakaran sampah yang bertujuan untuk mengurangi jumlah sampah organic yang akan dikirim ke TPA.

\section{UCAPAN TERIMA KASIH}

Kegiatan PKM ini tidak akan dapat terlaksana tanpa bantuan dan dukungan dari berbagai pihak, oleh sebab itu dalam kesempatan ini kami mengucapkan terimakasih yang sebesar-besarnya kepada LPPPM Universitas Triatma Mulya, Dekan Fakultas Bisnis dan Sosial Humaniora Universitas Triatma Mulya, Kepala Desa Cepaka, serta pihak-pihak yang tidak dapat disebutkan satu persatu.

\section{DAFTAR PUSTAKA}

Sekarningrum, Bintarsih. Yunita, Desi. dan Sulastri, Sri. (2017). Pengembangan Bank Sampah pada Masyarakat di Bantaran Sungai Cikapundung. Jurnal Pengabdian Kepada Masyarakat, Vol 1 No 1.

Widawati, Anik Sri. dan Ikmah. (2019). Pemberdayaan Masyarakat dalam Pengelolaan Sampah Rumah Tangga. Seminar Hasil Pengabdian Masyarakat. 